\title{
Tratamiento De Las Aguas De La Laguna "Mansión” Mediante La Especie Eichhorniacrassipes, Para El Riego De Áreas Verdes En La Universidad Peruana Unión
}

\author{
M. Cruz, N. Carbo, Javier L. L. Gonzales, G. M. Tito, K. Depaz, S. Torres,R. \\ Núñez, J. Torres, W. Quispe \\ E. P. Ingeniería Ambiental. Facultad de Ingeniería y Arquitectura. Universidad Peruana Unión. Lima, Perú
}

\begin{abstract}
Resumen: El propósito del estudio fue determinar la eficiencia de remoción de contaminantes del agua mediante la especie EichhorniaCrassipes para el riego de las áreas verdes en la Universidad Peruana Unión $(U P e U)$. Esta investigación surge de observar la contaminación del agua de superficie causada por la presencia de residuos urbanos, domésticos e industriales en el cuerpo de agua a tratar, reduciendo la calidad de esta fuente para riego y generar riesgos a la salud de las personas del campus universitario y otros destinos.El sistema de tratamiento se instaló en la zona denominada "La mansión", donde existe una laguna cuyas dimensiones son $3050.16 \mathrm{~m}^{2}$, profundidad $4 \mathrm{~m}$, volumen $6405.336 \mathrm{~m}^{3}$ y un caudal de $0.12 \mathrm{~m}^{3} / \mathrm{sg}$, con periodo de retención de 5 días para el tratamiento. Se implementó 37 sistemas flotantes ubicados alrededor y 7 en la zona intermedia de la laguna, posteriormente se sembró 600 plántulas de EichhorniaCrassipes. El muestreo del agua se realizó antes y al finalizar el tratamiento. Se evaluaron parámetros fisicoquímicos: $p H$ (8.22), aceites y grasas (4mg/l), sólidos totales (371 mg/l), turbiedad (18.40 UNT), conductividad (3.80 US/cm); microbiológicos: coliformes totales (24000 NMP/100ml), Coliformes Fecales (11000 NMP/100ml); Bioquímicos: (DBO $(3 \mathrm{mg} / \mathrm{L}), D Q O(25 \mathrm{mg} / \mathrm{L})$ ): Metales pesados: Arsénico total $(0.050 \mathrm{mg} / \mathrm{l} \mathrm{As})$, Plomo total $(0.153 \mathrm{mg} / \mathrm{l} \mathrm{pb})$, Cadmio (0.004ppm) y nutrientes: $\mathrm{N}$-Amoniacal $\left(0.022 \mathrm{mg} / \mathrm{NO}_{4}-\mathrm{N}\right)$, Nitratos $\left(0.10 \mathrm{mg} / \mathrm{l} \mathrm{NO}_{3}\right)$. Entretanto, el método estadístico que permitió analizar los datos, fue la prueba t, a través de la comparación de medias entre los parámetros estudiados. Finalmente, se concluye que la remoción de contaminantes del agua mediante la especie EichhorniaCrassipes para el riego de las áreas verdes en la UPeU es totalmente eficiente, ya que, a través del tratamiento de dichas aguas se consiguió establecer un sistema armonioso con el ambiente, útil para limpiar los residuos acuáticos, como los metales pesados y otros contaminantes, convirtiéndose en una vía cada vez más reconocida para desarrollar la capacidad de tratamiento en las aguas residuales sin demandar costos elevados.Palabras clave: tratamiento de agua, Eichhorniacrassipes, sistema flotante, contaminación, laguna.
\end{abstract}

\section{Introducción}

Según Rodie\&Hardenberg(1987), las aguas contaminadas provienen de diferentes fuentes, como pueden ser las industrias y las zonas habitacionales, por lo que están compuestas de partículas muy variadas, tanto en tamaño como en composición. Es así que la calidad del agua se establece como aquellas condiciones físicas, químicas y microbiológicas que deben darse en el agua para que ésta mantenga un ecosistema equilibrado. Por ello el diagnóstico de calidad del agua debe evaluar parámetros físicos, químicos y microbiológicos.

Debido a ello se plantean alternativas de tratamiento para aguas residuales, como el caso de la construcción de la Planta de Tratamiento de Aguas Residuales Carapongo en el año de 1988, cuya tecnología de tratamiento es la aplicación de lagunas aireadas, diseñada para tratar un caudal de $140 \mathrm{l} / \mathrm{s}$ de desagües de Chosica, Chaclacayo y poblaciones ribereñas (SEDAPAL, 2008), por otro lado está el sistema de tratamiento de aguas residuales con plantas acuáticas, el cual ofrece eficiencia y bajo costo para la depuración de aguas residuales, la remoción de microorganismos y contaminantes físicoquímicos, esto debido a la operación y mantenimiento frente a los sistemas convencionales actuales.

Celis, Junod, \& Sandoval (2005), mencionan que, la depuración de aguas residuales con plantas acuáticas flotantes es uno de los sistemas más utilizados, y consiste en canales de profundidad que fluctúan entre los 0.45 a $1.5 \mathrm{~m}$. Algunas de las especies que se utilizan son: Jacinto acuático, lenteja de agua y azolla.Las plantas acuáticas son aquellas que requieren una gran cantidad de agua en sus raíces para vivir, crecen en medios muy húmedos y completamente inundados. Según Caicedo (1995), éstas básicamente tienen los mismos requerimiento nutricionales de las plantas terrestres, pudiéndose clasificar en flotantes, sumergidas y emergentes. Durante los últimos años la población se ha triplicado mientras que el consumo de agua se ha sextuplicado. Según OPS (2001) el 90\% de los desagües de américa latina son vertidos sin ningún tratamiento a los ríos y mares o son usados en el riego de cultivos acuáticos de 500.000 hectáreas aproximadamente, 
Tratamiento De Las Aguas De La Laguna “Mansión” Mediante La Especie Eichhorniacrassipes,

generando problemas de salud pública y contaminación ambiental. Además, se estima que solo el $20 \%$ de aguas residuales producidas en el área urbana son tratadas pero solo se da efectivamente en un 10\% (Morales, 2008). Asimismo, Quipuzco (2004) menciona que en el Perú se producen alrededor de 1,000 millones de $\mathrm{m}^{3}$ de aguas residuales domésticas al año, de este volumen sólo el $22 \%$ es tratado, en Lima sólo es tratada el $9.5 \%$ y el resto es distribuido de diferentes maneras como el vertimiento en los cuerpos de agua como ríos, lagos; el uso para riego de cultivos agrícolas, etc.

Por todo ello, existe la necesidad de reutilizar las aguas residuales, ya sea para riego de vegetales, áreas verdes, bebida de animales, etc.; por lo cual, la presente investigación tiene como fin determinar la eficiencia de remoción de contaminantes del agua de la laguna "Mansion" mediante la especie EichhorniaCrassipes para el riego de las áreas verdes en la Universidad Peruana Unión (UPeU) Ñaña-Lima-Perú. Una técnica de tratamiento con bajos costos en ejecución, operación y mantenimiento, el cual debe encontrarse dentro de los parámetros establecidos por el Decreto Supremo 002-2008-MINAM Estándares de Calidad Ambiental para Agua en la Categoría 3: Riego de vegetales y bebida de animales.

\subsection{Sistema de cultivos acuáticos}

\section{Revision Bibliográfica}

Los cultivos acuáticos o sistema de plantas acuáticas flotantes consisten en el contacto que tiene el agua con la atmósfera y constituye la fuente principal de oxígeno para aireación; en la que se siembran plantas flotantes como Eichhorniacrassipes(ver figura 1), los cuales tienen la finalidad de eliminar los diversos compuestos de las aguas residuales a través de sus raíces que constituyen un buen sustrato para el tratamiento. (Celis, Junod, \& Sandoval, 2005).

Además de aportar tratamiento, las plantas flotantes evitan la entrada de la luz solar al estanque, deteniendo así el crecimiento de algas. Estos sistemas han sido utilizados también, como medios de producción de proteínas o biomasa, en cuyo caso la depuración de agua constituye un objetivo secundario del proyecto. Las funciones más importantes de las macrófitas en el tratamiento de las aguas residuales se relacionan con efectos físicos que se inducen en el mismo (Demirezen\&Akbulut, 2011).Los sistemas que utilizan plantas acuáticas flotantes, constituyen una alternativa, debido a la elevada capacidad de proliferación de contaminantes, absorción de contaminantes y la nula generación de lodos (Ramos, Rodríguez \& Martínez, 2007).

El funcionamiento de los sistemas naturales para tratamiento de aguas residuales, se basa en el sembrío de plantas acuáticas a lagunas de estabilización, humedales artificiales con plantas acuáticas (plantas flotantes y emergentes), canales de lecho de grava con plantas emergentes, organismos filtradores (peces, moluscos, etc.) e incluso la combinación de varios de estos sistemas (CEADU, 2006).

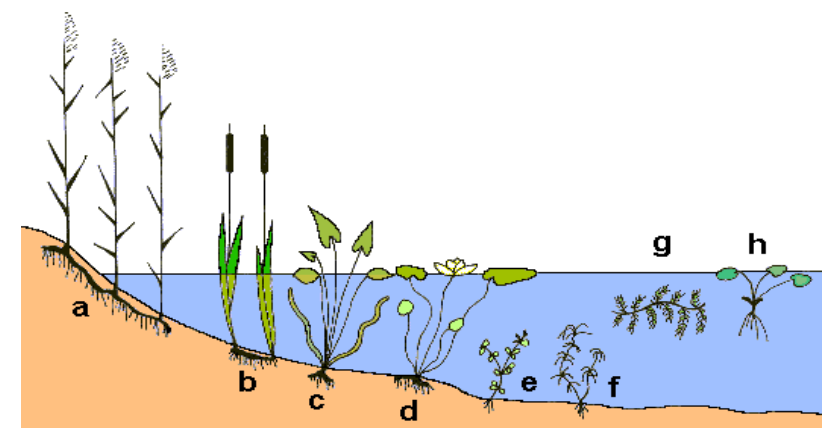

Figura 1: Cultivos acuáticos con macrófitas flotantes.

a b. plantas anfibias o palustres

c,d. plantas acuáticas arraigadas con hojas flotantes

e, f. plantas acuáticas arraigadas totalmente sumergidas

$\mathrm{g}, \mathrm{h}$. plantas acuáticas libres, sumergidas $(\mathrm{g}), \mathrm{y}$ flotantes libre $(\mathrm{h})$

\subsection{Función de las macrófitas acuáticas en el sistema de tratamiento}

Las funciones que cumplen las macrófitas acuáticas flotantes en los sistemas de tratamiento son: airear el sistema radicular y facilitar oxígeno a los microorganismos que viven en la rizósfera; absorción de nutrientes (nitrógeno y fósforo); eliminación de contaminantes asimilándolos directamente en sus tejidos y la filtración de los sólidos a través del entramado que forma su sistema radicular (Garcia, 2012).

\subsection{Jacinto de agua (Eichhorniacrassipes)}

El jacinto de agua (Eichhorniacrassipes) llamado comúnmente camalote o Jacinto de agua común, es una planta acuática de la familia de las Pontederiaceae (ver tabla 1). 
Tratamiento De Las Aguas De La Laguna “Mansión” Mediante La Especie Eichhorniacrassipes,

Tabla 1. Taxonomía del (Eichhorniacrassipes)

\begin{tabular}{|l|l|}
\hline Reino & Vegetal \\
\hline División & Manoliophyta \\
\hline Clase & Liliopsida \\
\hline Orden & Pontederiales \\
\hline Familia & Pontederiaceae \\
\hline Genero & Eichhornia \\
\hline Especie & Crassipes \\
\hline
\end{tabular}

Fuente: (Romero 2002)

La especie del Eichhorniacrassipes es originaria de las aguas dulces de las regiones cálidas de América del Sur en las cuencas Amazónica y del Plata (Cuevas, 2012). El jacinto de agua tiene alta capacidad de captación de metales pesados, tales como $\mathrm{Cd}, \mathrm{Cr}, \mathrm{Co}, \mathrm{Ni}, \mathrm{Pb}, \mathrm{Hg}$, que podría ser utilizado para la biolimpieza de aguas residuales industriales (ver figura 2).

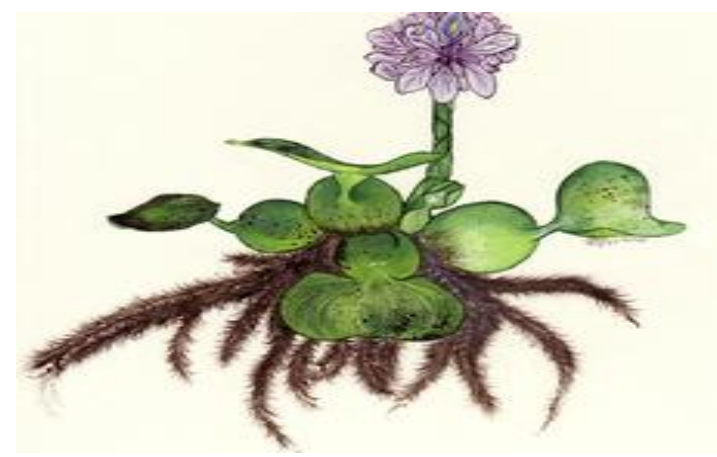

Fuente: (Romero, 2002)

Figura 2. Morfología de la Eichhorniacrassipes.

\subsection{Reproducción y cultivo}

Según Jaramillo \& Flores (2012), la reproducción del Jacinto de agua es sexual y asexual, se reproducen por propagación vegetativa y sus semillas son importantes debido al rebrote una vez que son eliminadas las plantas adultas. Asimismo Munavalli\&Saler (2009) mencionan que el Jacinto de agua se reproduce cada dos semanas, duplicando su cantidad inicial. El cultivo del Jacinto de agua se describe de dos formas; el primero, por el porcentaje de superficie de agua ocupada durante un determinado tiempo y el segundo, por la densidad de la planta medida como masa de plantas mojadas por superficie unitaria (Jaramillo \& Flores, 2012).

\subsection{Parámetros de crecimiento}

El crecimiento del jacinto de agua depende de una serie de factores entre los que se plantean las condiciones climáticas; los nutrientes presentes en el agua, los métodos de cosecha, la temperatura entre 25 a 30 ${ }^{\circ} \mathrm{C}$, para su óptimo crecimiento necesita un pH entre 6.5-7.5 (Rodríguez, 2002).Los principales mecanismos en el tratamiento del jacinto de agua, están las raíces, donde los microorganismos aerobios y anaerobios crecen y dan lugar a una mayor biodegradación de los residuos, estas actúan como sustrato vida de microorganismos adheridos, que luego proporcionan un grado significativo de tratamiento (Yadav, Jadhav, Chonde, \&Raut, 2011).

Estas plantas son capaces de crecer exitosamente sobre los efluentes y convertir los contaminantes biodegradables, en materiales útiles, como forraje rico en proteínas. Los estudios y monitoreo de campo indican un buen crecimiento relativo en agua cloacal y en efluentes de producciones pecuarias. La ventaja que tiene el utilizar la lenteja de agua para captar nutrientes, proviene de su preferencia por captar el amoníaco, es un buen acumulador de $\mathrm{Cd}$, Se y $\mathrm{Cu}$, asimismo es un acumulador moderado de $\mathrm{Cr}$ y pobre acumulador de $\mathrm{Ni}$ y $\mathrm{Pb}$ (RALCEA, 2013).Los jancitos de agua, no trabajan solas sino que conjuntamente con las bacterias ayudan a purificar el efluente. La descomposición bacteriana causa anaerobiosis, la cual es mantenida por la cobertura vegetal que se crea en la superficie y que evita la aireación. Dicha planta puede desarrollarse en un rango amplio de temperaturas, que varían entre $5^{\circ}$ y $30^{\circ} \mathrm{C}$, con un crecimiento óptimo entre $\operatorname{los} 15^{\circ}$ y $18{ }^{\circ} \mathrm{C}$. Se adaptan a cualquier condición de iluminación y crecen rápidamente en zonas calmadas y ricas en nutrientes, con altos niveles de fosfatos y nitrógeno, cabe resaltar que el nitrógeno es un elemento limitante para su adecuado desarrollo, además pueden tolerar un rango de $\mathrm{pH}$ amplio, siendo el óptimo entre 4.5 y 7.5 (ARROYAVE, 2004). 
Tratamiento De Las Aguas De La Laguna “Mansión” Mediante La Especie Eichhorniacrassipes,

\subsection{Descripción de la zona de estudio}

\section{Metodologia}

La zona de estudio es considerada como un refugio de aves silvestres y área de recreación denominada la Laguna "Mansión" tal como la fig. 1 muestra. Se encuentra ubicada a $580 \mathrm{msnm}$., a una latitud $0299741 \mathrm{~S}$, UTM 8672 262. El Área total es $3050.16 \mathrm{~m}^{2}$, una profundidad de $4.0 \mathrm{~m}$ y un volumen de $6405.336 \mathrm{~m}^{3}$.

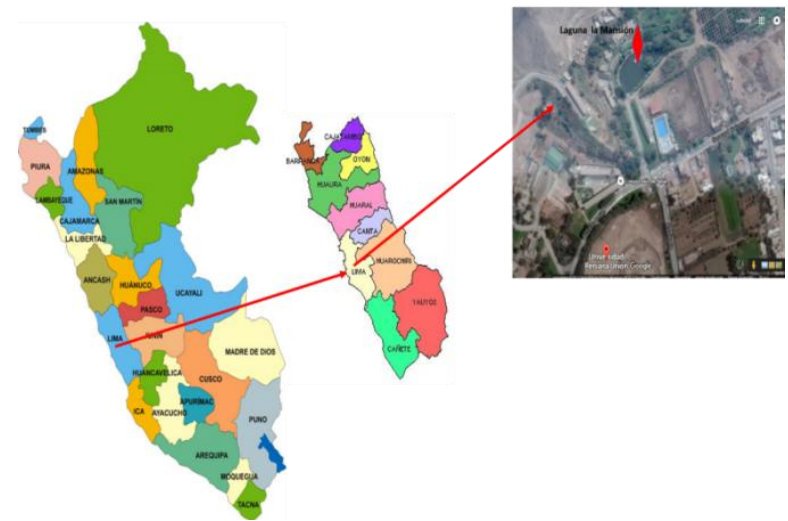

Figura 1. Zona de Estudio

\subsection{Desarrollo del proyecto}

El proyecto se desarrolló en cinco etapas:

\subsubsection{La primera etapa diagnóstico y acondicionamiento del lugar}

Para el sistema de tratamiento de estas aguas residuales se tuvo que realizar un diagnóstico general del centro de aplicación de la investigación, para posteriormente determinar los criterios de diseño, funcionamiento y el proceso interno de remoción de los nutrientes para ello se muestran datos en la tabla 2 así como ver el anexo 01 y el plano de toda la zona.

Tabla 2. Diagnóstico de campo para el tratamiento del agua

\begin{tabular}{|l|l|l|}
\hline \multicolumn{1}{|c|}{ Criterios de diseño } & Unidad de medida & Cantidad \\
\hline Área total de la laguna & $\mathrm{m}^{2}$ & 3499.00 \\
\hline Perímetro del lago & $\mathrm{m}$ & 278.86 \\
\hline Volumen de almacenamiento & $\mathrm{m}^{3}$ & 6405.336 \\
\hline Caudal de ingreso & $\mathrm{m}^{3} / \mathrm{sg}$ & 0.12 \\
\hline Periodo de ingreso & semanal & 1 \\
\hline
\end{tabular}

Una vez obtenido los datos de campo, se realizaron los cálculos para el proceso de tratamiento y así conocer el periodo de retención, siembra de las plantas y otros que se encuentran en la tabla 3, así como el plano diseñado en el anexo 02

Tabla 3. Criterios y dimensionamiento de diseño para el tratamiento del agua

\begin{tabular}{|l|l|}
\hline CRITERIOS DE DISEÑ & Jacinto de agua \\
\hline Macrófita empleada & $10{ }^{\circ} \mathrm{C}$ \\
\hline T mes mas frio & $0.68 \mathrm{~m}$ \\
\hline K25 & $0.95 \mathrm{~m}$ \\
\hline $\mathrm{H}$ & $0.50 \mathrm{~m}$ \\
\hline BL & 1.5 \\
\hline Z & $40 \%$ \\
\hline Porosidad & 10000 \\
\hline Ks & 2 \\
\hline Fs & $1 \%$ \\
\hline$\%$ S & 1 \\
\hline N & $3.00 \mathrm{mg} / 1$ \\
\hline Características del Agua Residual & $2.96 \mathrm{mg} / 1$ \\
\hline DBO5(a) & $1.33 \%$ \\
\hline DBO5(e) & $27648.0 \mathrm{~m} 3 / \mathrm{dia}$ \\
\hline$\%$ R DBO5 & $27648.0 \mathrm{~m} 3 / \mathrm{dia}$ \\
\hline Caudal & 0.28 \\
\hline Caudal unitario & $3452.1 \mathrm{~m} 2$ \\
\hline K10 &
\end{tabular}


Tratamiento De Las Aguas De La Laguna “Mansión” Mediante La Especie Eichhorniacrassipes,

Fuente: Propia

\begin{tabular}{|l|l|}
\hline Seccion transversal & $553.0 \mathrm{~m} 2$ \\
\hline Tiempo de retención & $0.05 \mathrm{~d}$ \\
\hline Dimensionamiento & $582.1 \mathrm{~m}$ \\
\hline We & $5.9 \mathrm{~m}$ \\
\hline Le & $584.9 \mathrm{~m}$ \\
\hline Wc & $8.8 \mathrm{~m}$ \\
\hline Lc & $579.2 \mathrm{~m}$ \\
\hline Wf & $3.1 \mathrm{~m}$ \\
\hline Lf & $3279.5 \mathrm{~m} 3$ \\
\hline V & $5-6$ dias \\
\hline Periodo de retención & 10 plantas $/ \mathrm{m} 2$ \\
\hline Siembra de la especie &
\end{tabular}

\subsubsection{Segunda Etapa: Muestreo y caracterización del agua de la laguna}

Para la caracterización del agua se tomaron muestras simples en botellas de polietileno de un litro. Para los parámetros físico-químicos, para $\mathrm{DB}_{5}$ en botella de vidrio color ámbar de $500 \mathrm{ml}$., para los parámetros microbiológicos en botellas de vidrio de $250 \mathrm{ml}$. Las muestras de agua se transportaron al laboratorio de calidad ambiental de la Facultad de Ciencias del Ambiente-Universidad Nacional Santiago Antúnez de Mayolo, Huaraz. Acreditado por el organismo peruano de acreditación Indecopi SNA Registro $\mathrm{N}^{\circ}$ LE-065. Los parámetros en estudio fueron: Fisicoquímicos: $\mathrm{pH}$, aceites y grasas $(4 \mathrm{mg} / \mathrm{l})$, sólidos totales, turbiedad, conductividad. Microbiológicos: coliformes totales, Coliformes Fecales. Bioquímicos: DBO5, DQO.Metales pesados: Arsénico total, Plomo total, Cadmio y Nutrientes: N-Amoniacal, Nitratos. Los métodos de análisis se muestran en la tabla 4 y los datos emitidos por el laboratorio se encuentran en el anexo 03.

Tabla 4. Resultados de los Análisis de agua

\begin{tabular}{|c|c|c|c|c|}
\hline PARÁMETRO & $\begin{array}{ll}\text { UNIDAD } & \text { DE } \\
\text { MEDIDA } & \\
\end{array}$ & MÉTODO & $\begin{array}{l}\text { LÍMITE DE } \\
\text { DETECCION }\end{array}$ & $\begin{array}{l}\text { MUES } \\
\text { TRA }\end{array}$ \\
\hline \multicolumn{5}{|l|}{ Análisis Fisicoquímicos } \\
\hline Aceites, y grasas & $\mathrm{mg} / \mathrm{l}$ & APHA 5520 B (*) & 1 & 4 \\
\hline $\begin{array}{l}\text { Conductividad } \\
\text { laboratorio) }\end{array}$ & & $\begin{array}{l}\text { APHA2510 B-Version } \\
2012\end{array}$ & $\ldots \ldots$ & 496 \\
\hline Fosfato & $\mathrm{mg} / \mathrm{l} \mathrm{P}$ & Vanadatomolibdato & 0.5 & $<0.5$ \\
\hline $\mathrm{pH}$ ( en laboratorio) & Unid.pH & $\begin{array}{ll}\text { APHA } & 4500 . \mathrm{H}^{*} \mathrm{~B} . \\
\text { Version } & 2012(*)\end{array}$ & $\ldots \ldots$ & 8.22 \\
\hline Solidos sedimentables & $\mathrm{mg} / \mathrm{l}$ & APHA $2540 \mathrm{~F}(*)$ & 1 & $<1$ \\
\hline Solidos totales & $\mathrm{mg} / \mathrm{l}$ & APHA $2540 \mathrm{~B}(*)$ & 1 & 371 \\
\hline $\begin{array}{l}\text { Solidos totales en } \\
\text { suspensión }\end{array}$ & $\mathrm{mg} / \mathrm{l}$ & APHA $2540 \mathrm{D}(*)$ & 1 & 18 \\
\hline Solidos Volatiles & $\mathrm{mg} / \mathrm{l}$ & APHA $2540 \mathrm{E}(*)$ & 1 & 81 \\
\hline $\begin{array}{l}\text { Temperatura } \\
\text { laboratorio) }\end{array}$ & ${ }^{\circ} \mathrm{C}$ & APHA 2540 B (*) & & 19 \\
\hline $\begin{array}{ll}\text { Turbiedad } & \text { (en } \\
\text { laboratorio) }\end{array}$ & UNT & APHA 2540 B (*) & 0.01 & 18.40 \\
\hline \multicolumn{5}{|l|}{ Metales Pesados } \\
\hline Arsénico total & $\mathrm{mg} / \mathrm{l} \mathrm{As}$ & Plata -DDTC $(*)$ & 0.050 & $<0.050$ \\
\hline Plomo total & $\mathrm{mg} / \mathrm{l} \mathrm{Pb}$ & PAR (*) & 0.010 & 0.153 \\
\hline \multicolumn{5}{|c|}{ Análisis de indicadores de contaminación bioquímica } \\
\hline $\begin{array}{l}\text { Demanda Bioquimica } \\
\text { de Oxigeno }\end{array}$ & $\mathrm{mg} / \mathrm{l} \mathrm{DBO5}$ & APHA 5210 B (*) & 1 & 3 \\
\hline $\begin{array}{l}\text { Demanda Quimica de } \\
\text { Oxigeno }\end{array}$ & $\mathrm{mg} / \mathrm{l} \mathrm{DQO}$ & $\begin{array}{l}\text { Oxidación } \\
\text { cromosulfurico }(*)\end{array}$ & 25 & $<25$ \\
\hline $\begin{array}{l}\text { Oxigeno disuelto ( en } \\
\text { laboratorio) }\end{array}$ & $\mathrm{mg} / \mathrm{l}$ & APHA 4500-OG $(*)$ & 0.01 & 6.66 \\
\hline \multicolumn{5}{|l|}{ Análisis de Nutrientes } \\
\hline N-Amoniacal & $\mathrm{mg} / \mathrm{l} \mathrm{N}$ & azul indofenol $(*)$ & 0.010 & 0.022 \\
\hline Nitratos & $\mathrm{mg} / \mathrm{l} \mathrm{N}$ & Nitrospectral (*) & 1.000 & $<1.0$ \\
\hline \multicolumn{5}{|c|}{ Indicadores de contaminación microbiológia e identificación de patógenos } \\
\hline Coliformes totales & $\mathrm{NMP} / 100 \mathrm{ml}$ & APHA 9221 B (*) & $<2$ & 24000 \\
\hline $\begin{array}{l}\begin{array}{l}\text { Coliformes fecales o } \\
\text { termotolerantes }\end{array} \\
\end{array}$ & $\mathrm{NMP} / 100 \mathrm{ml}$ & APHA $9221 \mathrm{C}(*)$ & $<2$ & 11000 \\
\hline \multicolumn{5}{|l|}{ Análisis parasitológico } \\
\hline Huevos de Helmintos & Huevos/1 & $\begin{array}{l}\text { APHA 9810B ; EPA } \\
1623(*)\end{array}$ & ausenia & $\begin{array}{l}\text { ausenci } \\
\text { a }\end{array}$ \\
\hline
\end{tabular}

Fuente: Laboratorio de calidad Ambiental FCAM-UNASAM 
Tratamiento De Las Aguas De La Laguna “Mansión” Mediante La Especie Eichhorniacrassipes,

\subsubsection{Tercera Etapa: Construcción e Instalación del sistema}

El sistema más viable desde el punto de vista social, económico y ambiental son los sistemas flotantes, estos fueron construidos con tubos de desaguepvc de 4 pulgadas, este material se consideró por la densidad del material superior al del agua, para la flotación respectiva, los dimensionamientos de estos sistemas son de $3 \mathrm{~m}$ de longitud y $0.50 \mathrm{~m}$ de ancho. Teniendo un área de cada sistema flotante de $1.5 \mathrm{~m}^{2}$. Se instalaron 35 sistemas flotantes, una vez concluida los sistemas el área total instalada con el sistema flotante y la especie EichhorniaCrassipesde $60 \mathrm{~m}^{2}$, los sistemas se ubicaron en el contorno hacia el lado Oeste de la laguna, siendo que en este espacio por la pendiente de inclinación al 1\% se acumula la gran cantidad de materia orgánica por la acumulación de los residuos sólidos y la acumulación de lodos, este aspecto nos favorece para la degradación de la materia orgánica y como nutriente para las especies, así también como un soporte para los pares de mampostería y como sostén para los sistemas flotantes. Ver el anexo 04.

\subsubsection{Cuarta Etapa: Implantación de Eichhorniacrassipes}

Jacinto de Agua (EichhorniaCrassipes) El Jacinto de agua es una de las macrófita flotante, planta perenne de agua dulce, Según (Lissy\& G., 2014) es muy eficiente en la eliminación de contaminantes como sólidos suspendidos, DBO, materia orgánica, metales pesados y agentes patógenos. La planta puede duplicar su población en solo 12 días. Posee la capacidad para crecer en aguas contaminadas, mejora la calidad de los efluentes de lagunas de oxidación.

Proceso de purificación La depuración de contaminantes según Martelo \& Borrero (2012), se da por tres mecanismos principales: filtración y sedimentación de sólidos, incorporación de nutrientes en plantas y la degradación de la materia orgánica por microorganismos facultativos asociados a las raíces de la planta.

La purificación del agua se da en el proceso de la fotosíntesis, los micrófitos flotantes (Jacinto de agua) emplean el oxígeno y dióxido de carbono disponible en la atmósfera e introducen al agua; los nutrientes son tomados de la columna de agua a través de las raíces, las cuales constituyen también un excelente medio para la filtración/adsorción de sólidos suspendidos y materia orgánica. Ver anexo 05.

\subsubsection{Quinta Etapa: Monitoreo del sistema de tratamiento}

Se realizó un sistema de monitoreo semanal para observar el proceso de tratamiento o los inconvenientes que se presentan en el tratamiento ya sean por factores internos o externos, tomándose en cuenta el caudal de ingreso a la laguna de acuerdo al diagnóstico de campo cada 7 días, ya que el canal de alimentación es por tramos y sectores de área a regar y a la laguna ingresa con el periodo mencionado, sin embrago por la época de estiaje de lluvia el ingreso se dió con retrasos de 9 -10 días, asimismo cuando hubo incremento de lluvia en las zonas altas el caudal de ingreso fue cada 5 a 6 días, estas variaciones del caudal de ingreso y el volumen de almacenamiento hizo una variación en el periodo de retención para la degradación de la materia orgánica mediante la especie, de la mismo modo por el incremento del agua el periodo de retención se demoró más de lo normal.

Se observó un crecimiento favorable de esta especie, siendo que hay variables que favorecen el crecimiento del Jacinto de agua; la alimentación de estas se da por los nutrientes de la alta concentración de materia orgánica. La laguna cuenta con animales silvestres por la presencia de peces siendo estos fuente de alimentación para las aves, la presencia de este sistema genero la carencia de alimentos para aves ocasionando que estas se alimenten de la especies plantadas para la depuración del agua (Eichhorniacrassipes), por lo que se implementó la protección de los sistemas con mallas para el crecimiento favorable.Ver anexo 06

Por otro lado se presenció la muerte de peces y aves signo de la alta contaminación de las aguas de la laguna por la presencia de grasas y aceites, en ocasiones se percibió a simple vista la presencia de hidrocarburos y por el olor emitido. Asimismo el incremento de las aves es a gran escala lo que genera la sobrepoblación y esto la carencia de alimentos ocasionado la muerte de ellos, estos caen a la laguna e incrementa la descomposición en el agua. Ver anexo 07.

\section{Resultados Y Discusión}

En cuanto a los resultados de la presencia de grasas y aceites se encuentra por encima del parámetro, se debe a que las principales fuentes aportadoras de grasas y aceites provienen de los usos domésticos, talleres automotrices, industria del petróleo, rastros, procesadoras de carnes y embutidos e industria cosmética, esto nos da entender que aguas arriba existen conexiones clandestinas que vierten a las aguas contaminando.Los LMP establecidos por el reglamento de la Calidad del Agua para riego de vegetales según el DS $\mathrm{N}^{\circ}$ 002-2008MINAM han establecido un nivel máximo aceptable de presencia de coliformes totales, $\mathrm{pH}$, temperatura, turbiedad, arsénico total, plomo total, oxígeno disuelto y Coliformes Fecales.

Para ello con base del muestreo y el análisis realizado en el laboratorio de calidad de agua se determinó si el agua que se utiliza para riego de vegetales de tallo bajo y alto es apta, los resultados del pre análisis del agua indicaron que los parámetros anteriormente mencionadas quedan fuera de los LMP establecidos por el 
mismo decreto, sin embargo luego de la aplicación del sistema se humedales con la Eichhorniacrassipes se obtuvo una mejoría de la calidad del agua tal como muestra la figura 2 y 3.

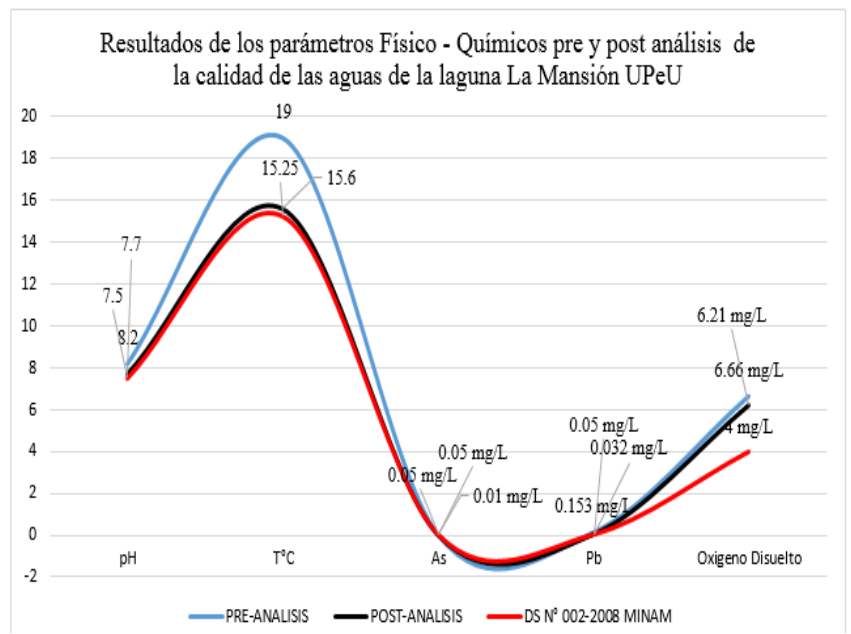

Figura 2.Resultados de la depuración de las aguas de la Laguna La Mansión de la UPeU

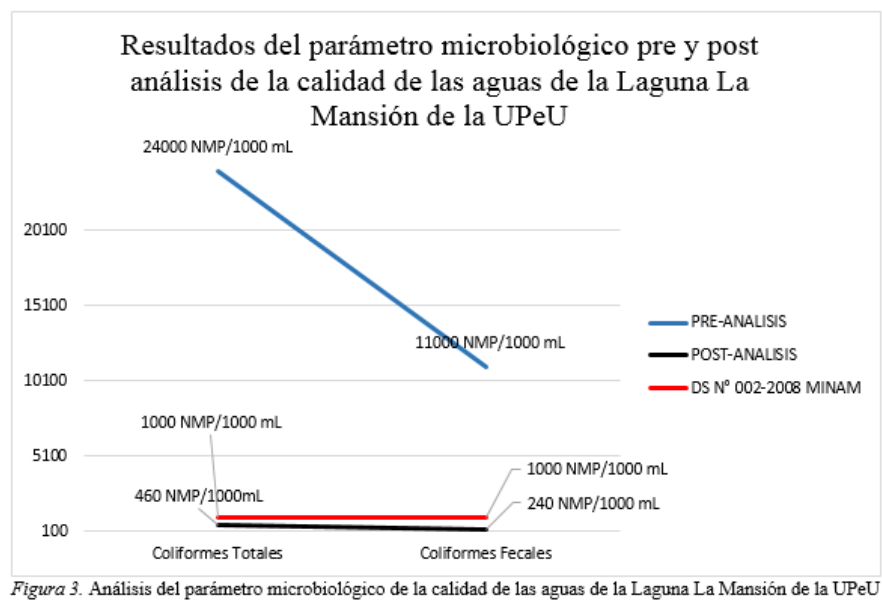

Figura 3. Análisis del parámetro microbiológico de la calidad de las aguas de la Laguna La Mansión de la UPeU

Para ver con claridad las figuras 2 y 3 ver en anexo 6.El pH de la mayoría de las aguas naturales esta entre 6 - 9 unidades. El pH permanece razonablemente constante a menos que la calidad de agua cambie debido a las influencias de tipo natural o antropogénicas, aumentando la acidez o la basicidad. Como la mayor parte las formas de vida ecológicas son sensibles a los cambios de $\mathrm{pH}$ es importante que el impacto antropogénico (por ejemplo, las descargas de efluentes) se han minimizado un afluente con un $\mathrm{pH}$ demasiado alejado del rango aceptable $6-8$ puede matar la colonia activa microbiología. Por lo cual es importante mantener el control de $\mathrm{pH}$ de los sistemas biológicos de tratamiento de aguas residuales dentro de un rango específico, en nuestro caso se ajusta a los estándares luego del sistema de tratamiento empleado.

La presencia de solidos totales que nos muestra en los resultados, se debe a que este parámetro es uno de los más significativos. La cantidad, el tamaño y el tipo dependen del agua específica, en el caso estudiado son provenientes de aguas domésticas y que por la actividad misma aguas arriba son de canal, vienen arrastrando solidos: arcilla, limo, arena entre otros, existe alta carga orgánica, estas aguas residuales en su mayoría contiene restos fecales y pueden tener materia de partícula orgánica, incluyendo trozos de comida en rango de milímetros. El contenido de sólidos de un agua afecta directamente la cantidad de lodos que se produce en el sistema de tratamiento o disposición.

La turbiedad y sólidos suspendidos guardan una estrecha relación, siendo que la presencia de sólidos en suspensión incrementa la turbidez del agua y la de los sólidos disueltos. Estos sólidos en suspensión producen el color aparente en las aguas en nuestro caso el color verde oscuro a un pardo, pero que disminuyen el paso de radiación solar, lo que lleva consigo una disminución de la fotosíntesis y muerte de las plantas a las que no les llega esta radiación. Estos depósitos de sólidos pueden acarrear problemas por crear condiciones anaerobias y pueden sedimentar en las aguas receptoras formando depósitos que destruyen la fauna del fondo (alimento de 
los peces) y los lugares de desove. Producen problemas en los peces debido a que se depositan en las branquias originado la muerte de la vida acuática.

La presencia del plomo y los compuestos de plomo son generalmente contaminantes tóxicos. Las sales de plomo II y los compuestos orgánicos del plomo son dañinos desde un punto de vista toxicológico. El plomo limita la síntesis clorofílica de las plantas. No obstante las plantas pueden absorber del suelo altos niveles de plomo, hasta $500 \mathrm{ppm}$. Concentraciones más altas perjudican el crecimiento de las plantas. El plomo en el agua residual proviene principalmente de las conexiones clandestinas de las viviendas, canales y de las calles, así como la mayor fuente de plomo en el agua puede ser de origen industrial, minero y de descargas de hornos de fundición o de cañerías viejas de plomo, y las construcciones cercanas. (MINSA-SEDAPAL, 25 de mayo de 2010), esto es un problema ya que en la laguna existe vida acuática tal es el caso de los peces y aves que estarían asimilando la presencia de plomo.

En el caso del arsénico, el parámetro no es significativo sin embargo si este parámetro se incrementa sería un peligro para la vida dentro de los cuerpos de agua, según (MINAM, 2008),la presencia del arsénico en la laguna "Mansión" se da por la actividad minera desarrollada durante antaño en la parte alta de la cuenca del río Rímac que ha vertido durante varias décadas volúmenes importantes de relaves mineros, por lo que constituye un alto riesgo de contaminación por metales pesados y por ende causa un impacto negativo en en las aguas de la laguna "Mansión" de la UPeU y la salud de las personas que viven alrededor (OMS, 2014)

Por la presencia de plomo y arsénico también se deduce la presencia de Cadmio y cromo, esto se debe a que aguas arriba existe actividad minera y este punto es la fuente de liberación de cadmio al medio acuático. Puede provenir del agua de drenado de minas, de las aguas residuales del procesamiento de los minerales, de derrames de los depósitos de desechos del proceso del mineral, del agua de lluvia que cae en el área general de la mina y de las partículas más ligeras de mineral, que pasan a través de los cedazos en las operaciones de concentración y purificación. (MINSA-SEDAPAL, 25 de mayo de 2010), el cadmio no es detectable fácilmente por el límite del método de análisis empleado para la determinación de esta, por lo que se presume la ausencia del mismo o una baja concentración de significancia irrelevante.

En cuanto a la presencia del DBO, nos da entender aguas arriba en el tramo del canal, existen presencia de desecho de alguna industria, y que las viviendas vierten sus aguas en todo el trayecto de transporte, están son mezcladas. Se deduce la presencia de industrias clandestinas que no tienen ningún pre tratamiento para verter sus aguas por la alta presencia de DBO.

El oxígeno disuelto adecuado se necesita para una buena calidad del agua. El oxígeno es un elemento necesario para todas las formas de vida. Los procesos de purificación naturales de la corriente requieren niveles de oxígeno adecuados para facilitar las formas de vida aeróbicas. La vida acuática está bajo tensión, a concentración más baja, mayor tensión. Los niveles de oxígeno que permanecen bajo 1-2 mg/L par unas pocas horas pueden resultar en largas agonías para los peces. Peces, invertebrados, plantas y bacterias aeróbicas, todos requieren oxígeno para la respiración. Mucho del oxígeno disuelto en el agua viene de la atmósfera. Después de la disolución en la superficie, el oxígeno se distribuye por la corriente y la turbulencia. Las algas y las plantas acuáticas también ceden oxígeno al agua mediante la fotosíntesis. El principal factor que contribuye a los cambios en los niveles de oxígeno disuelto es el crecimiento de residuos orgánicos. El decaimiento de los residuos orgánicos, es por ello que se puede observar la muerte de peces de 2 a 5 peces muertos por semana siendo que el nivel del oxígeno disuelto es muy elevado.

$\mathrm{N}$ - Amoniacal, es uno de los componentes transitorios en el agua puesto que es parte del ciclo del nitrógeno y se ve influido por la actividad biológica. Es el producto natural de descomposición de los compuestos orgánicos nitrogenados. En el agua puede aparecer en forma molecular o como ion amonio, dependiendo del pH. Las aguas superficiales no deben contener normalmente amoniaco. En general, la presencia de amoníaco libre o ion amonio es considerado como una prueba química de contaminación reciente y peligrosa. $\mathrm{Si}$ el medio es aerobio, el nitrógeno amoniacal se transforma en nitritos, la presencia se puede entender a la presencia de fábricas de gas, la recolección de aguas de lluvia, tras un periodo de sequía, en zonas industriales, el incremento de aguas residuales agrícolas (excrementos de animales, basuras, fertilizantes), la descomposición de productos nitrogenados orgánicos en el suelo y la putrefacción de plantas.

La presencia de coliformes totales presentes en el agua se debe a la alta concentración de la carga orgánica, siendo que nos muestra que la presencia es alta y por ello que provienen directamente de un uso doméstico que invariablemente estarán en aguas que contienen E. coli y por tanto serán indicadores de contaminación fecal. Así mismo estos coliformes contienen un gran grupo de bacterias que viven normalmente en el tracto digestivo de los seres humanos y los animales. Por esta razón, estos microorganismos se encuentran en las aguas residuales presentes en el lago. Sin embargo, muchos coliformes son inofensivos y se pueden encontrar en otros lugares tales como en las sustancias húmicas provenientes de los suelos. Por desgracia, los resultados muestran la alta concentración de este parámetro y que su origen son las viviendas clandestinas de desagüe y más aún si hay la presencia de animales cercanos. 
Tratamiento De Las Aguas De La Laguna “Mansión” Mediante La Especie Eichhorniacrassipes,

En cuanto a los coliformes fecales, existe una contaminación bacteriológica por organismos fecales en la laguna, ya que se detectó la presencia de estas bacterias en los puntos de muestreo, La presencia de este indicador indica, sin ninguna duda, que el agua presenta contaminación fecal y, por tanto, puede contener también bacterias patógenas provenientes de la actividad humana.

Así mismo la presencia de este indicador se puede decir que probablemente existan conexiones de desagüe directos al canal incrementando la carga orgánica y sobre todo microbiana, también existan la presencia de animales se encuentran casi exclusivamente cercanas a los cuerpos de agua tal es el caso de los gansos, aves y la descomposición de restos que alteraran la calidad natural del agua.Uno de los resultados que se puede constatar en campo es la disminución del olor fétido de heces de aves que se acumulan en los cuerpos de agua, y gracias a esta especie se puede demostrar que se removió olores desagradables y nauseabundos propios de las aves y de la descomposicón de los residuos sólidos.

\section{Conclusión}

La remoción de contaminantes del agua mediante la especie EichhorniaCrassipes para el riego de las áreas verdes en la UPeU es totalmente eficiente, ya que, a través del tratamiento de dichas aguas se consiguió establecer un sistema armonioso con el ambiente, útil para limpiar los residuos acuáticos, como los metales pesados y otros contaminantes, convirtiéndose en una vía cada vez más reconocida para desarrollar la capacidad de tratamiento en las aguas residuales sin demandar costos elevados.

\section{Recomendaciones}

En cuanto a la presencia continua de grasas y aceites se recomienda colocar las trampas de grasa, que son un sistema totalmente diseñado y construido para separar la grasa y aceite de las aguas residuales urbanas o industriales. Dicha grasa y aceites, así separadas, quedan atrapadas dentro del tanque y solamente se deja pasar por el sistema el agua "clarificada" que va al cuerpo receptor en nuestro caso la laguna y la vida acuática conservada.Un control adecuado el ingreso de agua, el cumplimiento de los horarios, para que así no se vea afectado el periodo de retención de se pueda cumplir el periodo de retención.

Ampliación e incremento de sistemas flotantes en la otra mitad del contorno, para mayores resultados de remoción de la carga orgánica.Un plan de manejo en cuanto al incremento de especies como las aves y peces, siendo que vienen alterando el ecosistema natural, y estos vienes generando la sobrepoblación.Estudio y análisis de las especies de la vida acuática para conocer si estos vienen asimilando los metales pesados.Limpieza continua de la canalización y de las cámaras de rejas para la minimización de los residuos sólidos en el agua y siendo un agente de muerte para las aves y la fotosíntesis de la flora y fauna acuática.El revestimiento total o por etapas del canal, para la facilidad de la limpieza, la operación de la cámara de rejasMantenimiento del sistema de bombeo interno y externo, ya que se pudo observar que también libera aceites en el momento de impulsar la bomba y esto actúa como un contaminante.Mejoramiento del puente ya que se encuentra deteriorándose y esto es un peligro para la población que acostumbra visitar la zona.

\section{Agradecimientos}

A la facultad de Ingeniería y Arquitectura por permitir haber desarrollado el proyecto con el financiamiento para todo el proceso de tratamiento, y de permitir generar nuevos conocimientos de investigación en los docentes como en los estudiantes del equipo de investigadores A la escuela profesional de ingeniería ambiental que vio la necesidad de participar en beneficio de la naturaleza en el tratamiento de estas aguas contaminadas de la laguna Mansión siendo este un lugar recreativo y muy visitado por la población estudiantil de la Universidad Peruana Unión y pobladores que viven cerca.

\section{Referencias Bibliográficas}

[1]. Arroyave, M. d. (febrero de 2004). La Lenteja de agua (Lemnaminor L.): Una planta acuática promisoria. REVISTA EIA(1), 33-38.

[2]. Bonilla Barbosa, J., \& Santamaría Araúz , B. (2013). bonilla@uaem.mx. Obtenido de http:// www. biodiversidad. gob.mx/ especies/Invasoras/pdf/acuaticas-invasoras-cap13.pdf

[3]. Borrero, J. A. (2012). Macrófitas flotantes en el tratamiento de aguas residuales; una revisión del estado del arte. Ingenieria y Ciencia, ing.cienc. ISSN 1794-9165, 221-243.

[4]. Celis, J., Junod, J., \& Sandoval, M. (01 de Junio de 2005). Recientes aplicaciones de la depuracion de aguas residuales con plantas acuaticas. Recuperado el 18 de Abril de 2014, de Recientes aplicaciones de la depuracion de aguas residuales con plantas acuaticas: http://www.ubiobio.cl/theoria/v/v14/a2.pdf

[5]. Celis, J., Junod, J., \& Sandoval, M. (2005). Recientes aplicaiones de la depuración de aguas residuales con plantas acuáticas. Theoria, 17-25.

[6]. Cuevas, Z. (2012). Utilización de Jacinto de Agua para Tratamiento. Obtenido de Utilización de Jacinto de Agua para Tratamiento: http://www.concytec.gob.pe/portalsinacyt/images/stories/corcytecs/moquegua/xxii_fencyt_2012_ca_moquegua.pdf

[7]. Del Pilar Arroyave, M. (Febrero de 2004). Recuperado el 29 de Abril de 2014, de http://revista.eia.edu.co/articulos1/3.pdf

[8]. Demirezen, D., \&Akbulut, H. (2011). Effect of circulationo nwastewat ertreatmentbyLemna Gibba and Lemnaminor (floatingaquaticma crophytes). International Journal of Phytoremediation, 970-984. 
Tratamiento De Las Aguas De La Laguna “Mansión” Mediante La Especie Eichhorniacrassipes,

[9]. García, M. (2012). Comparación y evaluación de tres plantas acuaticas para determinar la eficiencia de remocion de nutrientes en el tratamiento de aguas domesticas. Recuperado el 19 de Abril de 2014, de Comparación y evaluación de tres plantas acuaticas para determinar la eficiencia de remocion de nutrientes en el tratamiento de aguas domesticas: http://www.lima-water .de/ documents/zgarcia_tesis.pdf

[10]. Garcia, Z. (2012). Comparación y evaluación de tres planats acuáticas para determinar la eficiencia de remoción de nutrientes en el tratamiento de aguas residuales domésticas. Obtenido de Comparación y evaluación de tres planats acuáticas para determinar la eficiencia de remoción de nutrientes en el tratamiento de aguas residuales domésticas: http://ac.els-cdn.com/S0925857413004230/1s2.0-S0925857413004230-main.pdf?_tid=340ca71e-d2f5-11e4-9d54-

[11]. Jaramillo, M., \& Flores, E. (2012). Fitorremediación mediante el uso de dos especies vegetales Lemnaminor (Lenteja de agua) y Eichhorniacrassipes (Jacinto de agua) en aguas residuales producto de la actividad minera. Obtenido de Fitorremediación mediante el uso de dos especies vegetales Lemnaminor (Lenteja de agua) y Eichhorniacrassipes (Jacinto de agua) en aguas residuales producto de la actividad minera: http://dspace.ups.edu.ec/handle/123456789/2939

[12]. M. Meerhof, N. M. (2004). Importancia de las plantas flotantes libres .ecosistemas, 13-22.

[13]. Morales, G. (2008). Tendencia en investigación en Ingeniería Ambiental. Medellín: Sello Editorial.

[14]. RALCEA. (Agosto de 2013). Recuperado el 21 de Abril de 2014, de http:/ /www. aquaknow. net/en/system /files/4 .Lagunas\%20con\%20macr\%C3\%B3fitas.pdf

[15]. Red MAPSA. (junio de 2007). Guía para la utilización de las Valijas Viajeras-Conductividad. Obtenido de Guía para la utilización de las Valijas Viajeras-Conductividad.

[16]. Rodie, E., \&Hardenberg. (1987). Tratamiento de aguas residuales. Recuperado el 19 de Abril de 2014, de Tratamiento de aguas residuales: http://catarina.udlap.mx/u_dl_a/tales/documentos/lar/oropeza_b_vm/capitulo4.pdf

[17]. Rodríguez, C. (2002). Obtención de parámetros cinéticos en sistemas acuáticos con jacinto de agua. Obtenido de Obtención de parámetros cinéticos en sistemas acuáticos con jacinto de agua: http://www.bvsde.paho.org/bvsaidis/aresidua/peru/cubtar002.pdf

[18]. SEDAPAL. (abril de 2008). Planta de tratamiento de aguas residuales Carapongo. Obtenido de Planta de tratamiento de aguas residuales Carapongo: http://www.vivienda.gob.pe/direcciones/RESUMENES_EJECUTIVOS/009-2006.pdf

[19]. Trapote, A. (2011). Depuración de aguas residuales urbanas. San Vicente: Unión de Editoriales Universitarias Espeañolas.

[20]. Yadav, S., Jadhav, A., Chonde, S., \&Raut, P. (2011). Performance Evaluation of Surface Flow Constructed Wetland Systemby Using EichhorniacrassipesforWastewaterTreatment in anInstitutionalComplex. Universal Journal of EnvironmentalResearch and Technology, 435-441

\section{Anexos}

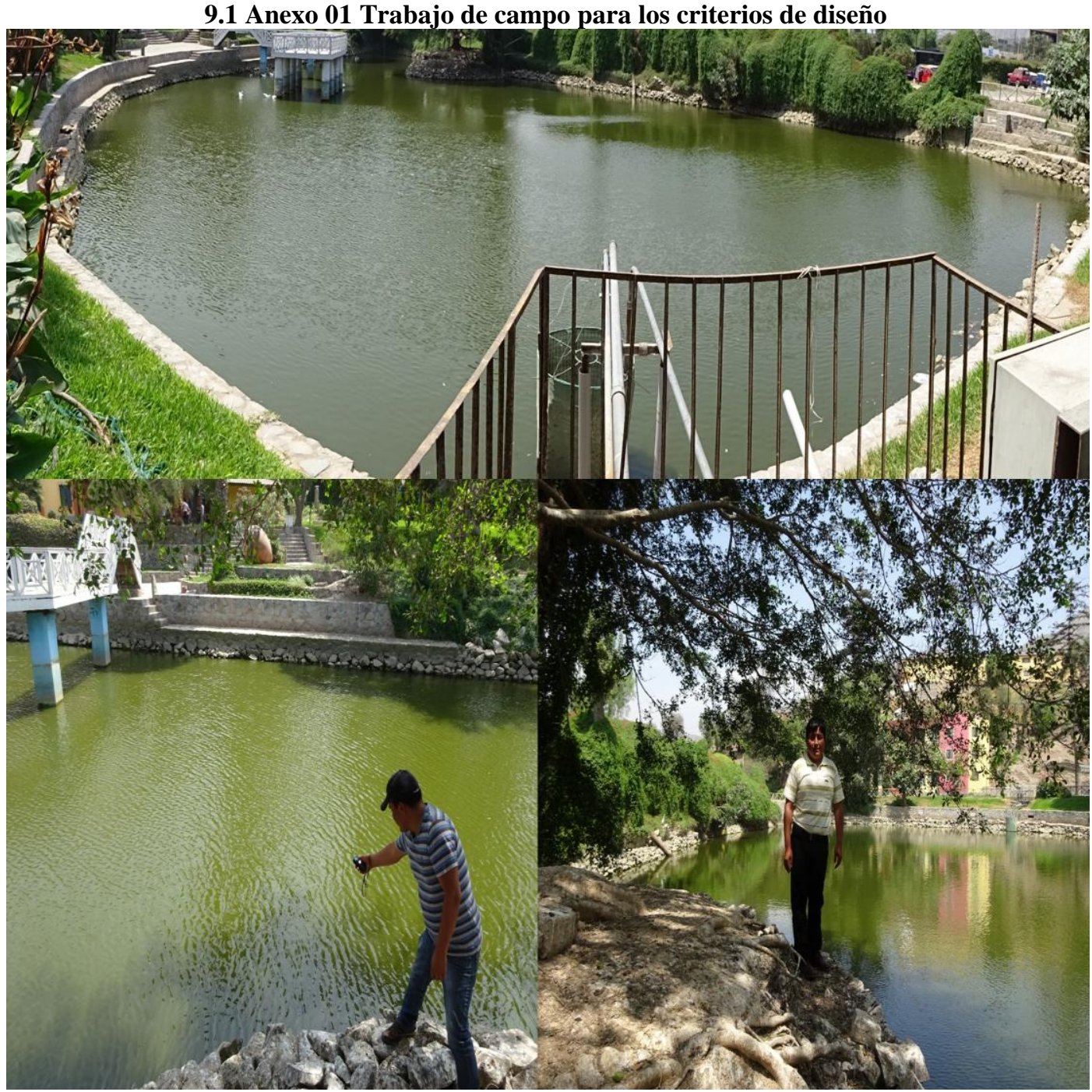


Tratamiento De Las Aguas De La Laguna “Mansión” Mediante La Especie Eichhorniacrassipes,

\subsection{Anexo 02 Plano general de la zona de investigación}

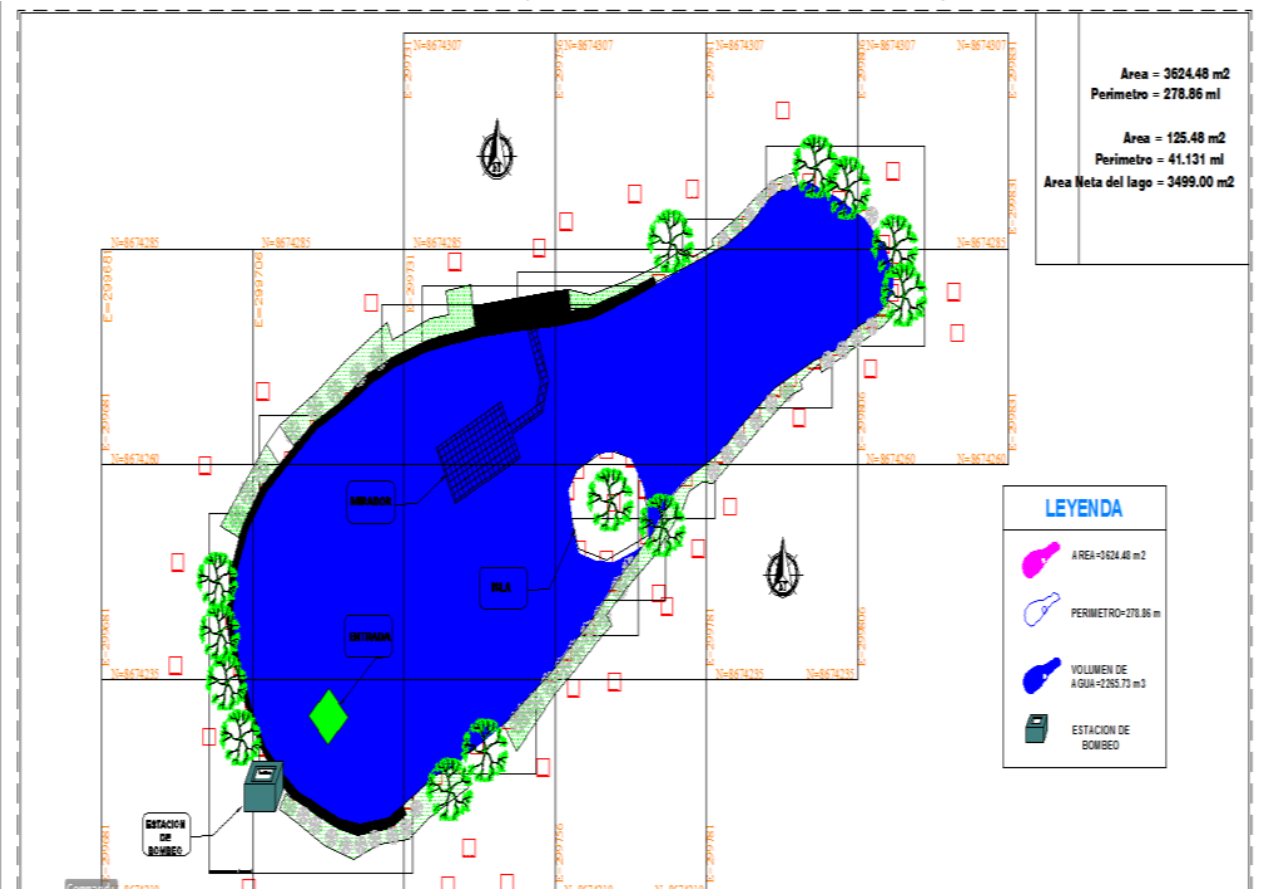

9.3 Anexo 03 Resultados de los análisis de laboratorio.
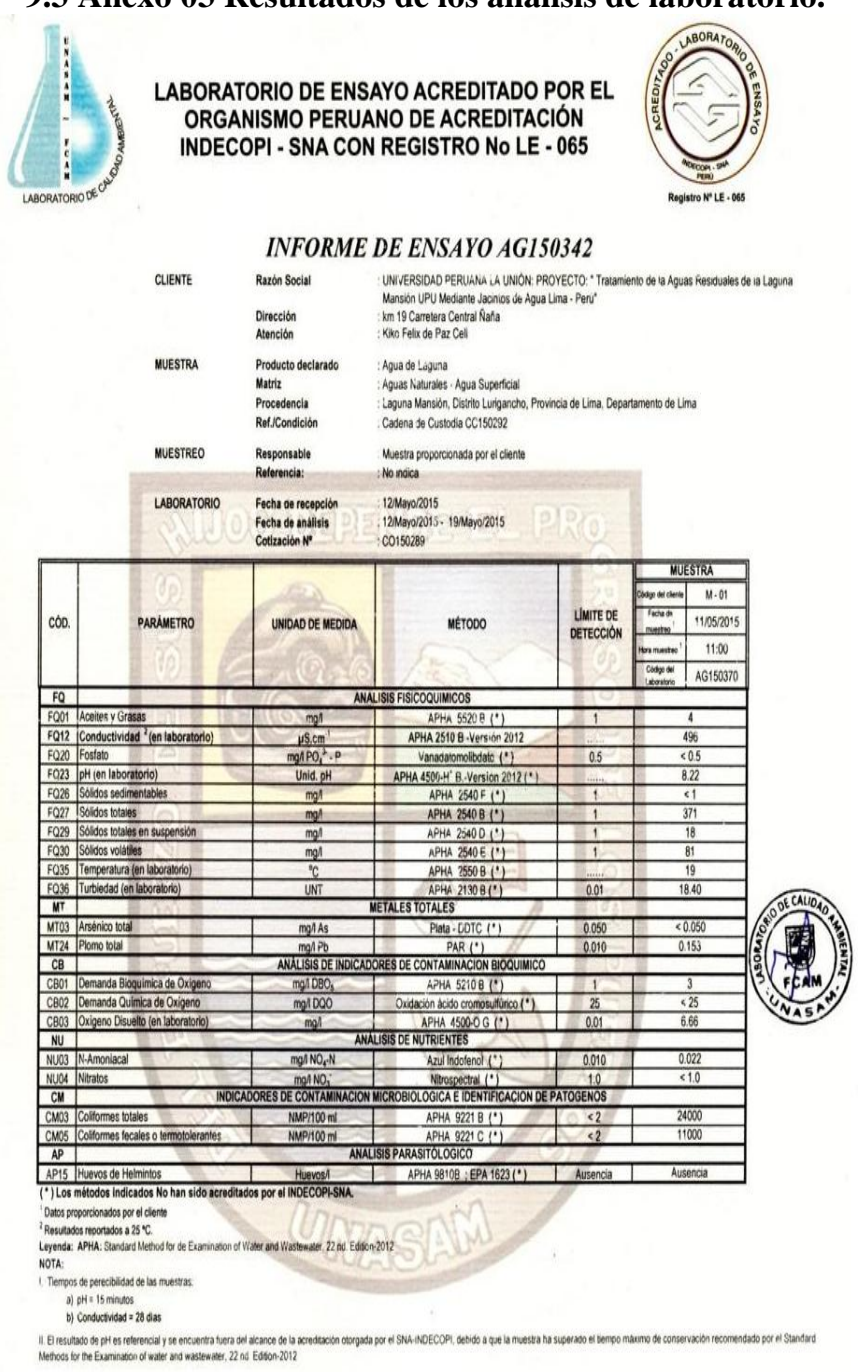
Tratamiento De Las Aguas De La Laguna “Mansión” Mediante La Especie Eichhorniacrassipes,

9.4 Anexo 04 Instalaciones de los sistemas flotantes y siembra de las especies
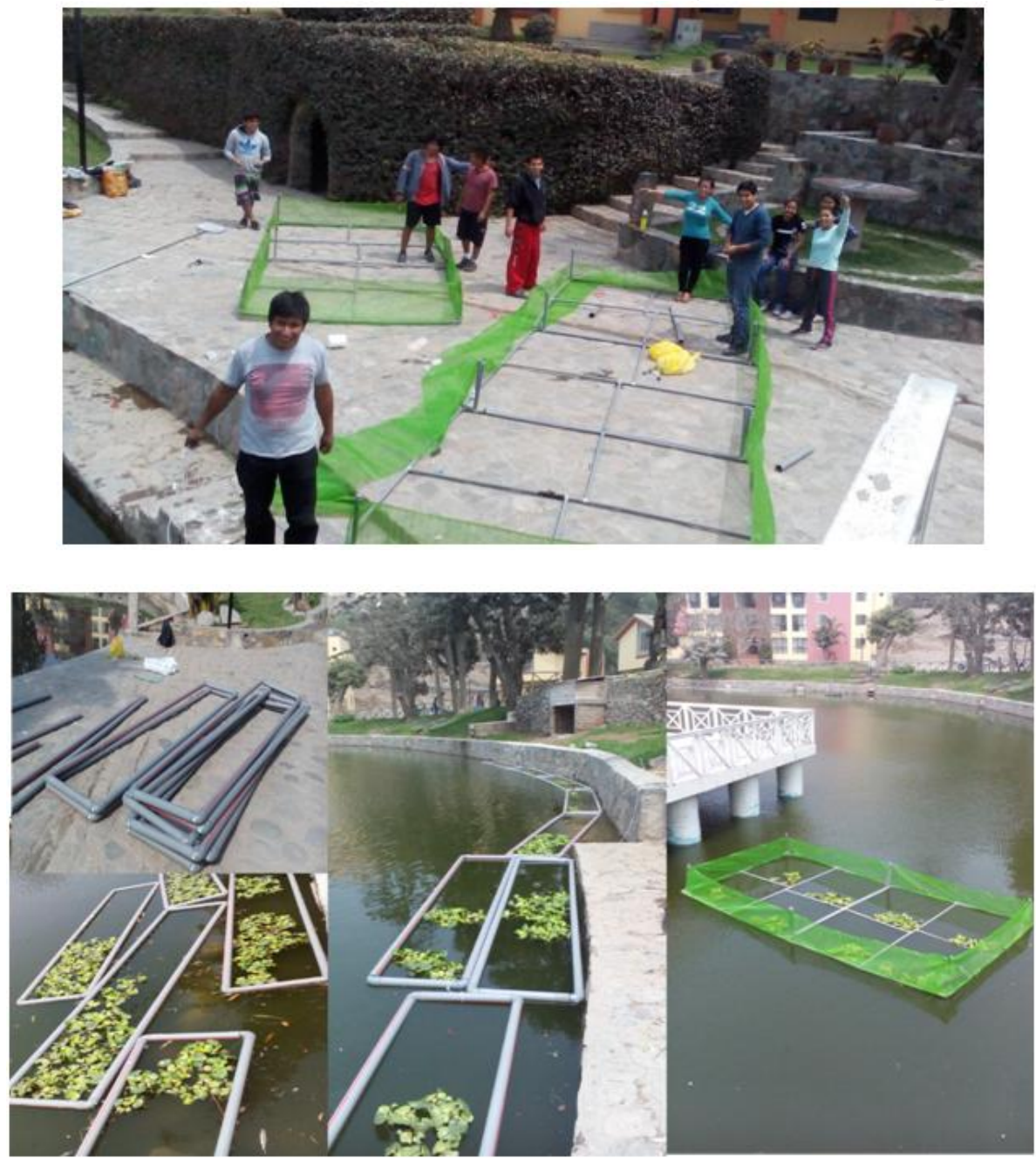

9.5 Anexo 05 Siembra de las especies
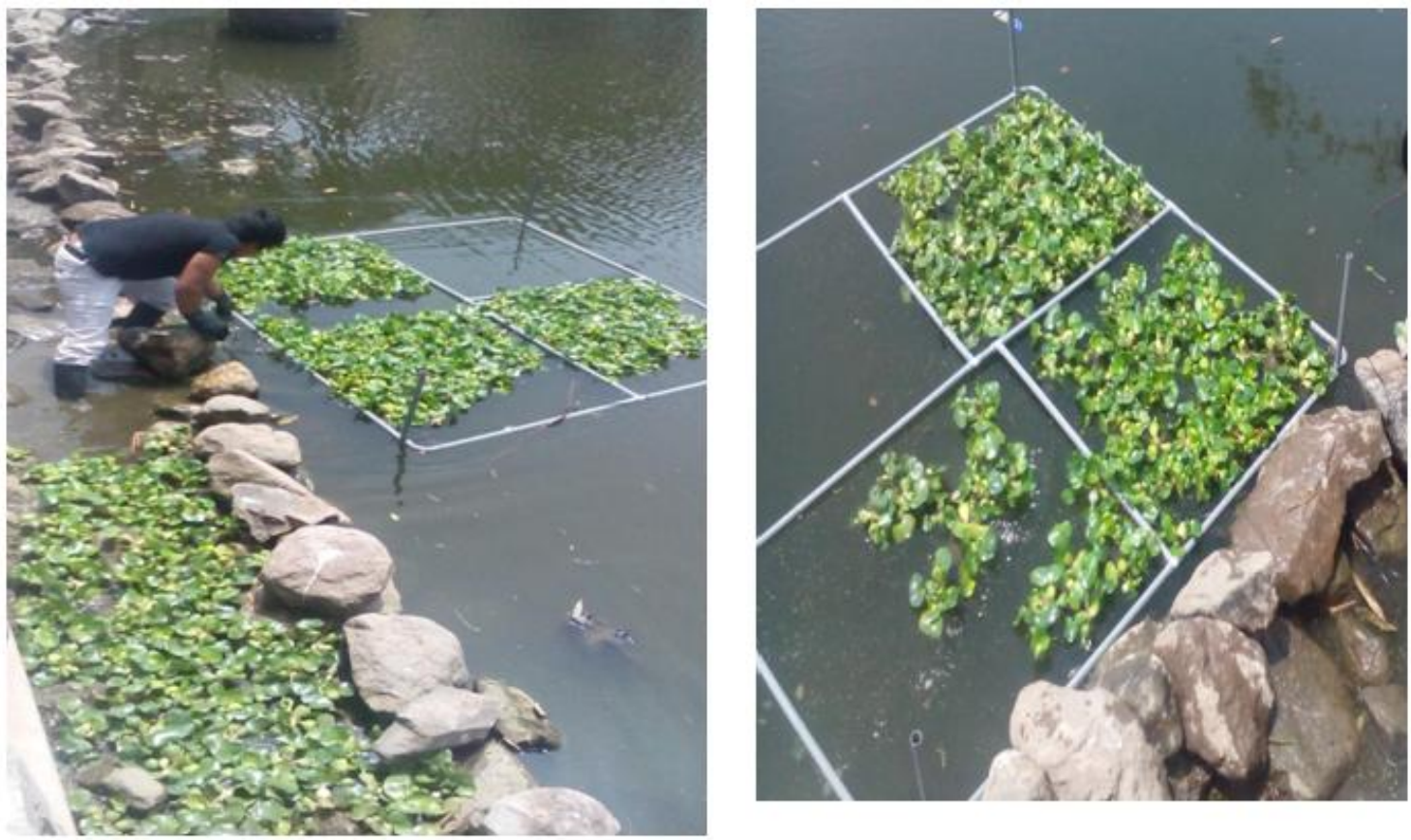

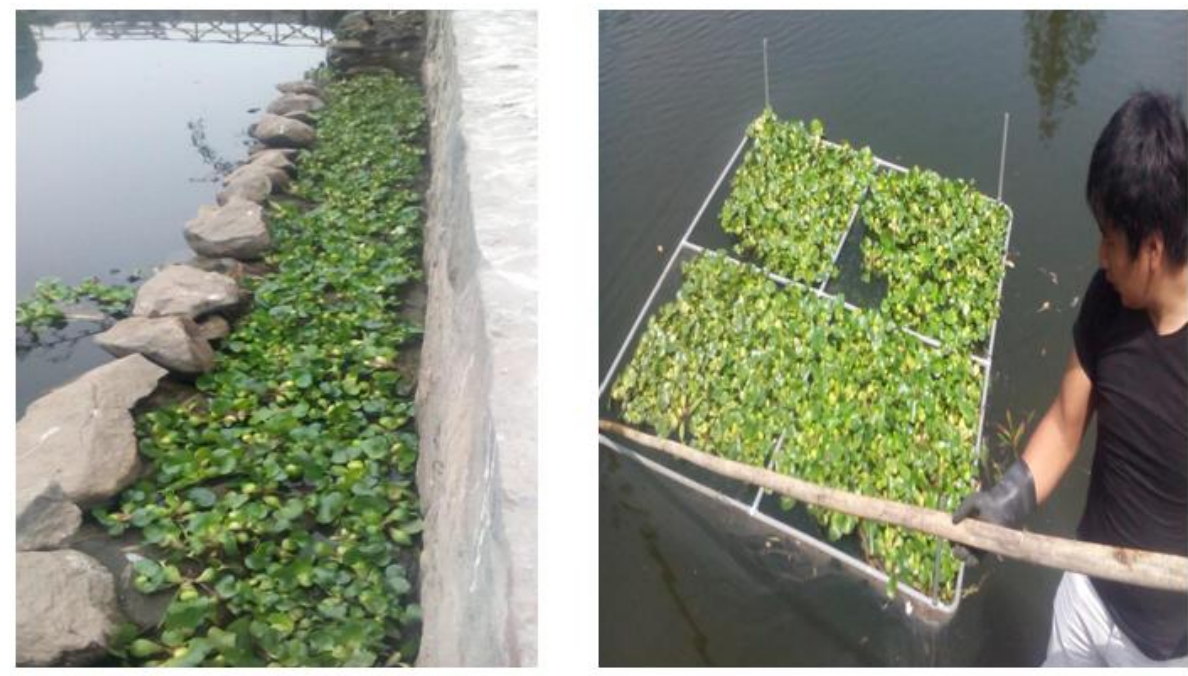

\subsection{Anexo 06}

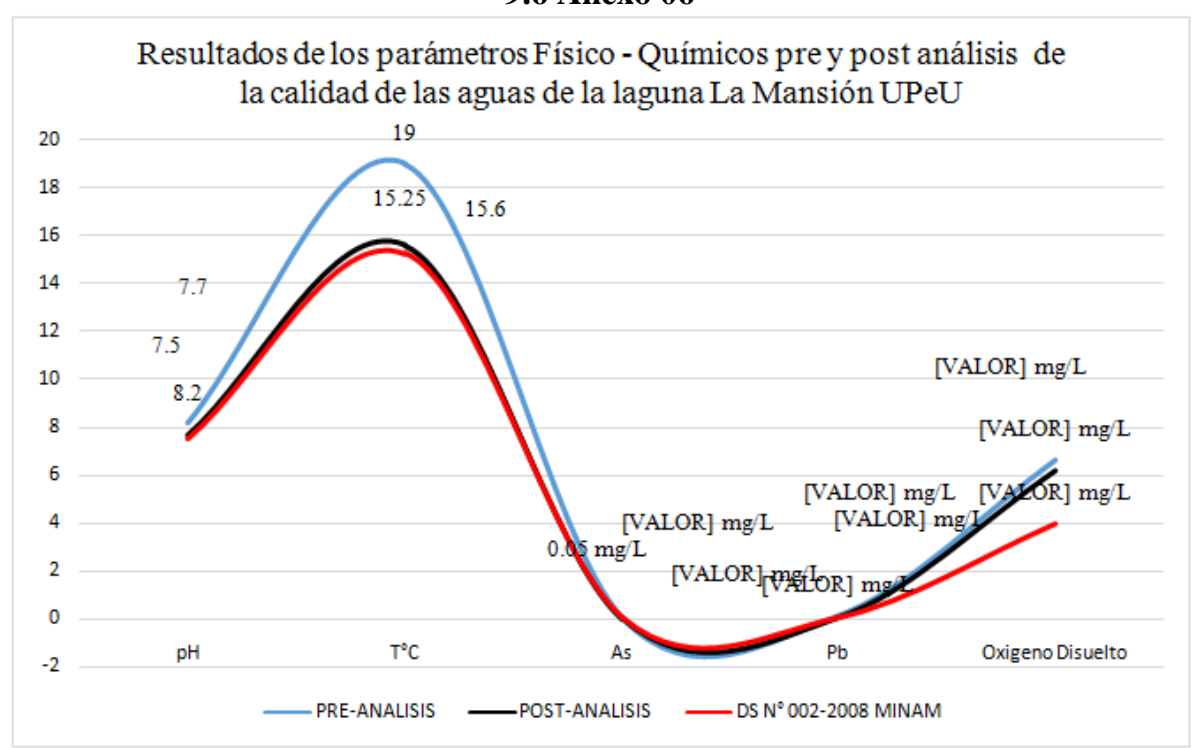

Figura 2.Resultados de la depuración de las aguas de la Laguna La Mansión de la UPeU

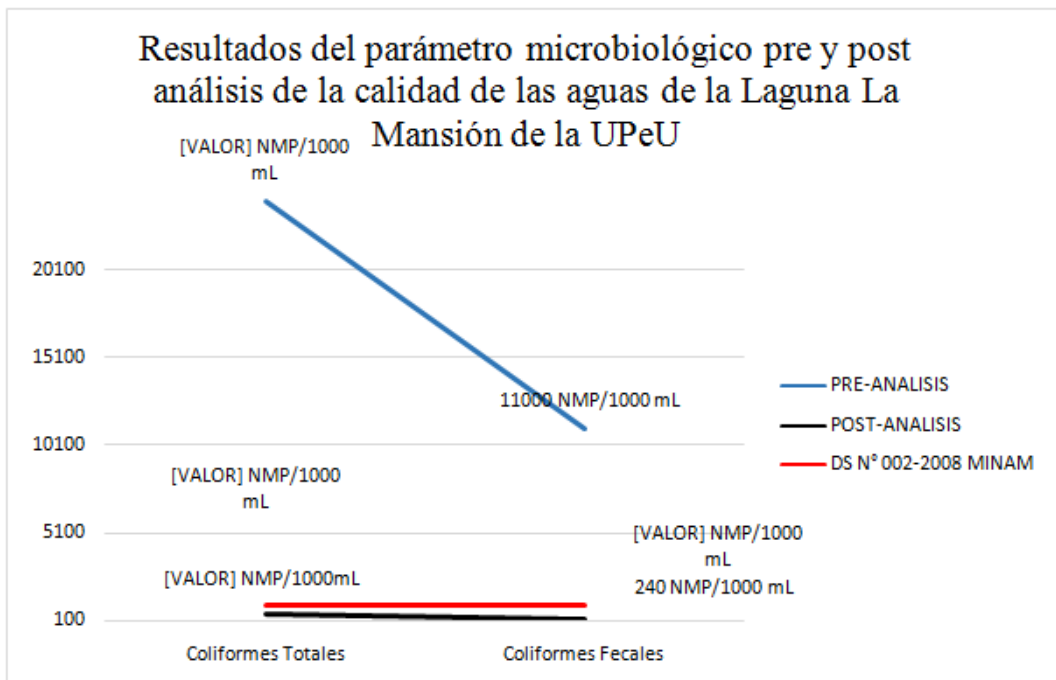

Figura 3. Análisis del parámetro microbiológico de la calidad de las aguas de la Laguna La Mansión de la $\mathrm{UPeU}$ 